\title{
Pengungkapan Jumlah Segmen Pasca Konvergensi IFRS
}

\author{
Dian Surya Ayu Fatmawati*, \\ Bambang Subroto, Aulia Fuad Rahman \\ Magister Ilmu Akuntansi, Fakultas Ekonomi, Universitas Brawijaya \\ Jl. MT. Haryono No. 165, Malang, Jawa Timur, Indonesia \\ *Email Koresponden: dyansurya76@gmail.com
}

159

Diterima:

01 Agustus 2018

Direvisi:

25 Oktober 2018

Disetujui:

29 Oktober 2018

Artikel ini tersedia di website: http:// ejournal.umm.ac.id/ index.php/jrak

The purpose of this study is to examine what extent of disclosure segmental reporting after IFRS convergence in Indonesia. The great value of this study is highlighted by the effort to empirically investigate the beginning impact of segmental disclosure standard to segment number. Descriptive analysis was used to describe changes of Line Of Business (LOB) segment, geographical segment, level of specificity number. The study consist of 32 Multinational company that listing in Indonesian Stock Exchange (ISE) at 2012-2017. Thus result show that number and types of segments reported decrease $4 \%$ for $\mathrm{LOB}$ and $2 \%$ for geographic segment and using more disaggregated at geographic level. Those findings about changing can help to lead an insight of segmental disclosure implementation in the future.

Keywords: Geographic segment; LOB segment; Number of segments; Segment Operating

\section{PENDAHULUAN}

Standar pelaporan segmen telah berubah di Indonesia dalam satu dekade terakhir ketika Indonesia memutuskan untuk menggunakan acuan International Financial Reporting Standard (IFRS) pada 1991. Hal tersebut selain karena Indonesia merupakan salah satu anggota G-20, pertimbangan berbagai kondisi hukum Indonesia dengan US yang berbeda sehingga US GAAP sebagai acuan terdahulu tidak selalu cocok dengan kondisi di Indonesia (Martani dkk, 2012). Selanjutnya, dalam melakukan konvergensi IFRS, Indonesia menggunakan gradual strategy yakni konvergensi yang dilakukan secara bertahap, seperti yang banyak dilakukan oleh negara berkembang dan menetapkan konvergensi penuh IFRS pada 1 Januari 2012. Keputusan mengkonvergensi International Financial Reporting Standard (IFRS), menyebabkan pelaporan segmen dipandang sebagai sesuatu yang berbeda. IFRS- 8 sebagai sumber konvergensi untuk PSAK-5R memberikan kriteria segmen usaha yang berbeda dari pendahulunya. Berdasarkan PSAK-5R kriteria segmen usaha memperbolehkan manajerial perusahan memutuskan dari 'kaca mata manajemen', dimana segmen tersebut harus dikaji ulang oleh Chief Operating Decision Maker (CODM) dan memiliki informasi keuangan terpisah. Sisi komprehensif dari PSAK-5R juga ditekankan, dimana identifikasi segmen yang dilaporkan pada periode kini dan lalu harus dilaporkan meskipun tidak memenuhi syarat (kualitatif dan kuantitatif). Beberapa pengungkapan yang belum diatur dalam PSAK-5 diperjelas oleh PSAK-5R. Perbedaan tersebut menjadikan International Accounting Standard Board (IASB) sebagai Penyusun IFRS, percaya bahwa keharusan entitas untuk melaporkan informasi segmen dengan menggunakan pendekatan yang sesuai dengan IFRS-8 dapat menekan biaya dan waktu yang dibutuhkan untuk menghasilkan informasi segmen. Penggunaan kaca mata manajemen dalam penyusunan laporan segmen, menjadikan laporan ini sarat akan informasi yang bernilai dalam perspektif pengambilan keputusan strategis oleh manajemen. Berbagai segmen yang potensial dalam perspektif manajemen yang diungkapkan oleh perusahaan dianggap mampu menurunkan penilaian risiko pasar dalam pelaporan (Radebaugh dan Gray, 2002).
Doi: $10.22219 /$

jrak.v8i2.35

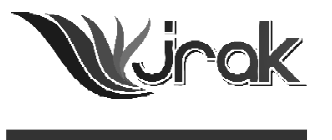

Jurnal Reviu Akuntansi dan Keuangan p-ISSN: 2615-2223 e-ISSN：2088-0685 Vol. 8 No. 2, Oktober 2018 Pp 159-166 
Pengungkapan Jumlah

Segmen...

160
Pelaporan segmen juga diyakini mampu menyajikan forecasting yang akurat dibandingkan dengan laporan agregat (Baldwin, 1984, Boatsman et al., 1993, Nichols, et al., 1995, Herrmann, 1996, Birt dan Shailer, 2011) karena dalam penyajian informasi segmen dalam bentuk disagregat berdasarkan jenis bisnis atau lingkungan geografis mampu menyajikan kondisi yang lebih rinci dan detil terkait kemungkinan risiko dan kondisi makro yang menyertainya. Jika perusahaan menggunakan line of business (LOB) sebagai segmen utamanya, maka para stakeholder beranggapan bahwa laporan tersebut mampu menyajikan informasi yang lebih relevan (Maines et al., 1997) karena mampu menunjukkan informasi secara komprehensif dari segmen-segmen yang memiliki kesamaan kondisi jenis bisnisnya dan kemampuannya untuk mengimplementasikan harapan-harapan stakeholder di masa depan. Penggunaan model forecast pendapatan dengan menggunakan data penjualan dan laba segmen line of Business (LOB) yang lebih akurat dibandingkan dengan data agregat dibuktikan oleh Lobo et al., (1998). Sedangkan jika perusahaan menggunaakan geografis sebagai segmen primernya, maka informasi tersebut diklaim lebih berguna dan informatif (Ettredge et al., 2005; Behn et al., 2002), karena pelaporan berdasarkan kondisi geografis mampu merefleksikan kondisi makro ekonomi yang dihadapi serta risiko-risiko yang berkaitan dengannya dan lebih diminiati investor karena memungkinkan investor untuk lebih memahami performance suatu segmen dan kaitannya dengan kegiatan-kegiatan asing diluar geografis wilayahnya (Hope et al., 2009). Jadi, penggunaan segmen primer berdasarkan line of business (LOB) maupun segmen geografis dianggap mampu memberi informasi yang dibutuhkan dan diminati oleh investor.

Kesadaran akan pentingnya pelaporan segmen ternyata berdampak terhadap perdebatan standar pelaporan yang digunakan. Isu yang paling nyata yakni perdebatan terkait pelaporan segmen menggunakan standar lama (IAS 14) dan (IFRS 8). Perdebatan tentang standar tersebut disinyalir sarat akan politisasi berbagai kepentingan dan kekuasaan (Crawford et al., 2014; Veron, 2007). Kekhawatiran terbesar yakni jika IFRS 8 akan relatif mengurangi keandalan dan komparabilitas informasi segmental dibandingkan IAS 14R (Veron, 2007). Investor menyatakan cukup prihatin pula tentang adanya kelonggaran yang diberikan kepada manajer dalam memilih aspek bisnis apa yang dilaporkan, serta khawatir tentang adanya penghapusan segmentasi geografis, yang dianggap penting bagi para Investor. Karena perdebatan tersebut, Parlemen Eropa melalui IASB melaksanakan sebuah Review pasca pelaksanaan (Post Implementation Review/ PIR) dari IFRS 8. Hasil PIR menyimpulkan bahwa sementara ini Standard bekerja dengan baik, adapun hal terkait perdebatan merupakan dampak dari pandangan investor yang beragam (IASB, 2013). Pentingnya informasi yang diungkapkan dalam laporan segmen menjadikan perubahan standar yang mengaturnya disoroti dan diperdebatkan oleh pihak-pihak yang berkepentingan. Perubahan informasi yang diungkapkan akibat perubahan standar mendesak untuk diteliti. Artikel ini mencoba menginvestigasi sejauh mana perubahan standar berdampak pada jumlah dan jenis segmen yang diungkapkan dan jenis segmen geografis yang diungkapkan. Perubahan standar dalam periode ini dapat menjadi acuan untuk mengetahui manfaat dan implementasi laporan segmen dalam jangka panjang.

\section{METODE PENELITIAN}

Populasi yang digunakan dalam penelitian ini yakni seluruh perusahaan yang listing di Bursa Efek Indonesia (BEI). Populasi ini dipilih karena pelaporan segmen, merupakan pelaporan segala jenis perusahaan yang melakukan segmentasi, diversifikasi maupun ekspansi. Teknik pengambilan sampel yang digunakan dalam penelitian ini adalah metode purposive, menggunakan perusahaan multinasional yang terdaftar di Bursa Efek Indonesia dalam periode 2012-2017 serta mengungkapkan informasi segmen. Pengukuran Jumlah dan jenis segmen dilaporkan berdasarkan prosentase jumlah segmen dan jenis segmen (geografis 
atau Line of Business). Sedangkan untuk pengukuran segmen geografis dengan mengkategorikan level segmen geografis kedalam kategori yang dikemukakan oleh Aleksanyan dan Danbolt (2015) dan yaitu (1) Segmen satu negara (2) Segmen dua negara (3) Segmen wilayah/benua tunggal (4) Dua-atau-lebih-wilayah/duaatau-lebih-benua (5) Segmen dunia. Hasil perhitungan berdasarkan tingkat prosentase dioerbandingkan dalam masing-masing periode. Perbandingan tersebut, akan dianalisa berdasarkan kedalaman teori dan penjelasan fenomena tersebut secara deskriptif. Hal tersebut dilakukan untuk memahami dan menjelaskan lebih dalam fenomena perubahan tersebut berdasarkan perspektif teori dan analisa penulis.

\section{HASIL DAN PEMBAHASAN}

\section{Jumlah Segmen Operasi Pasca Konvergensi IFRS}

Dari 32 perusahaan multinasional yang digunakan sebagai sampel, terdapat 40,6\% atau 13 Perusahaan merupakan perusahaan multinasional yang memiliki induk di luar negeri, sedangkan sisanya sebesar 59,4\% atau sebanyak 19 perusahaan merupakan perusahaan induk dari dalam negeri. Sebesar $81,25 \%$ dari total sampel atau sebesar 26 perusahaan menggunakan lini bisnis sebagai segmen primer dan segmen geografis sebagai segmen sekunder, dan sisanya yakni 18,75\% atau sekitar 6 perusahaan menggunakan segmen geografis sebagai segmen primer dan segmen bisnis sebagai segmen sekunder mereka. Hal tersebut disinyalir karena Perusahaan menganggap bahwa menggunakan segmen segmen LOB sebagai segmen primer lebih menarik investor sebab lebih mencerminkan kinerja perusahaan dibandingkan menggunakan segmen geografis. Fakta tersebut juga menunjukkan bahwa mayoritas perusahaan juga cenderung kurang menyukai data geografis yang komprehensif daripada data LOB.

Perbedaan jumlah primer segmen yang dilaporkan dimana perusahaan lebih banyak menggunakan segmen primer LOB dengan segmen geografis hanya sebagai segmen sekunder, ternyata tidak berlaku terhadap jumlah segmen. Perusahaan rata-rata mengungkap jumlah segmen sebesar 3,08 segmen pada kurun tahun 2012-2017, dari jumlah segmen tersebut, 55\% menggunakan segmen LOB dan sisanya sebesar $45 \%$ mengungkapkan segmen geografis sebagai segmen primer. Hal ini tentu saja karena kecenderungan kompleksitas bisnis peusahaan multinasional yang tidak mampu dijelaskan dalam satu segmen saja, diperlukan segmen sekunder untuk menunjang informasi yang diungkapkan agar lebih informatif karena Indonesia memiliki keragaman wilayah geografis yang perlu untuk diungkap secara lebih detil. Selain itu, pengungkapan segmen geografis tidak hanya berdasarkan pada penjualan, namun beberapa perusahaan mengungkapkannya berdasarkan jumlah asset dan liabilitas.

\begin{tabular}{lc}
\hline Keterangan & $2012-2017$ \\
\hline Total Sampel & 3,080 \\
Rata-rata jml segmen per Perusahaan & 1,692 \\
Rata-rata jumlah segmen LOB per Perusahaan & 1,388 \\
Rata-rata jumlah segmen geo per Perusahaan & \\
Perusahaan dengan segmen LOB sbg segmen primer & 3,141 \\
Rata-rata jml semua segmen per Perusahaan & 1,929 \\
Rata-rata jumlah segmen LOB per Perusahaan & 1,212 \\
Rata-rata jumlah segmen geo per Perusahaan & \\
Perusahaan dengan segmen Geo sbg segmen primer & 2,819 \\
Rata-rata jml semua segmen per Perusahaan & 0,667 \\
Rata-rata jumlah segmen LOB per Perusahaan & 2,152 \\
Rata-rata jumlah segmen geo per Perusahaan &
\end{tabular}


Pengungkapan Jumlah

Segmen...

162
Perusahaan dengan segmen LOB sebagai segmen primer juga cenderung lebih banyak memiliki jumlah segmen LOB dibandingkan segmen geografis, dimana dari 3,14 pengungkapan segmen LOB sebagai segmen primer, perusahaan mengungkapkan segmen geografis sebagai segmen sekunder hanya dengan porsi sebesar 38,5\% segmen. Hal tersebut karena pengungkapan informasi segmen disini merupakan aspek sekunder, dimana berdasarkan IFRS8, pengungkapan harus berdasarkan pertimbangan dari CODM, di Indonesia berbagai segmen pasar yang beragam dan kondisi geografis yang sangat luas mengahmbat beberapa perusahaan untuk memisahkan segmennya berdasarkan segmen geografis. Hal tersebut didukung fakta bahwa konsekuensi pengungkapannya akan meningkatkan biaya pengungkapan yang tinggi. Sedangkan perusahaan dengan segmen gegrafis sebagai segmen primer, tetap mengungkapkan segmen LOB sebagai segmen sekunder, namun dengan proporsi yang lebih sedikit yakni dari total pengungkapan 2,82 hanya 23,6\% yang merupakan pengungkapan LOB sebagai segmen sekunder. Hal tersebut karena perusahaan dengan segmen primer geografis, seringkali hanya memiliki satu cabang bisnis, namun melakukan ekspansi wilayah secara luas.

Rata-rata segmen operasi pada perusahaan MNC pasca konvergensi IFRS mengalami penyebaran yang stabil, dimana tidak ada yang sangat dominan hingga tidak menggunakan segmen yang lain. Agaknya perusahaan berusaha memenuhi harapan dari para stakeholder untuk mengungkapkan informasi yang berkualitas dengan menyajikan informasi segmen secara proporsional. Pilihan perusahaan untuk menggunakan suatu segmen sebagai segmen primer dalam konteks di Indonesia adalah dominasi keperluan dalam pengungkapan. Jika perusahaan memiliki dominasi keperluan untuk memetakan jumlah asset/liabilitas/pendapatan dalam masing-masing segmen dalam keragaman geografis, maka perusahaan akan cenderung mengungkapkan segmen geografis sebagai segmen primer mereka dengan focus pada aspek tersebut dan sebaliknya.

\section{Jumlah Segmen Berdasarkan Line Of Business (LOB) dan Geografis}

Perubahan jumlah segmen dari total keseluruhan sampel menunjukkan perubahan yang beragam, misalnya pada awal tahun konvergensi IFRS yang ditunjukkan Y1, penurunan pada segmen geografis, namun peningkatan yang tidak terlalu besar pada segmen LOB, hal tersebut karena pada beberapa industry seperti JAPFA, LPKR, MAPI memutuskan untuk mengurangi jumlah segmen geografis yang diungkakan secara signifikan.

Secara nilai, penurunan paling signifikan ditunjukkan oleh kedua segmen baik segmen geografis maupun segmen LOB, dimana penurunan secara keseluruhan sampai pada 6 tahun terakhir berkisar 4\% untuk segmen LOB dan $2 \%$ untuk segmen geografis. Perilaku pelaporan ini dapat dirasionalisasikan melalui lensa teori biaya kepemilikan, jika mengasumsikan bahwa data keuangan geografis yang mengungkapkan kinerja di lokasi geografis tertentu dengan variasi produk tertentu menjadi lebih sensitif secara komersial. Selain itu, biaya kepemilikan potensial memberi kemungkinan pengurangan manfaat masa depan yang dapat diatribusikan pada suatu pengungkapan. Pengungkapan data akuntansi tentang perusahaan dapat berguna bagi pesaing dan investor dengan cara yang berbahaya bagi prospek perusahaan bahkan jika (atau karena) informasi tersebut menguntungkan (Verrecchia, 1983). Manajer menghadapi trade-off antara biaya kepemilikan dan reaksi negatif investor terhadap pengungkapan terbatas oleh perusahaan, dan, menurut Scott (1994), hal tersebut dilakukan dengan membandingkan biaya pengungkapan informasi kepemilikan terhadap pengurangan yang diantisipasi dalam nilai perusahaan yang dihasilkan dari persepsi investor tentang apa yang mungkin disembunyikan. Pengungkapan informasi keuangan rinci pada produk dan operasi geografis tertentu dapat membahayakan posisi kompetitif perusahaan di lokasi yang diberikan dan juga memperingatkan berbagai otoritas pajak nasional ke daerah-daerah dengan profitabilitas sangat tinggi (atau rendah). 


\begin{tabular}{lcccccc}
\hline Keterangan & Y1 & Y2 & Y3 & Y4 & Y5 & Y6 \\
\hline Segmen LOB & 0,094 & $-0,063$ & $-0,125$ & 0,063 & $-0,219$ & 0,000 \\
Segmen Geografis & $-0,125$ & 0,000 & 0,219 & $-0,031$ & $-0,219$ & 0,000 \\
\hline
\end{tabular}

Penurunan pasca konvergensi IFRS merupakan respon yang dilakukan oleh perusahaan terkait berbagai kondisi peraturan yang ada. Perusahaan bisa jadi menggunakan penurunan tersebut selain sebagai respon adanya kerugian kompetitif terkait biaya pengungkapan, juga sebagai representasi atas penggunaan kaca mata manajemen dalam pengungkapan segmen (Fatmawati dan Pratiwi, 2018).

\section{Jumlah Segmen Berdasarkan Geografis}

Perusahaan dengan menggunakan segmen geografis sebagai segmen primer memiliki level pengungkapan segmen geografis yang konsisten, selama periode pengamatan 6 perusahaan sampel tersebut konsisten mengungkapkan dalam level yang beragam. Dari kelima kategori, perusahaan di Indonesia cenderung tidak mengungkapkan dengan menggunakan kategori kedua. Perusahaan memiliki keleluasaan dalam menentukan tingkat kekhususan segmen geografis atau area untuk tujuan pelaporan. Disatu sisi lain, agregasi geografis heterogen yang berlebihan daerah-daerah menjadi satu segmen geografis atau area yang dapat dilaporkan mengurangi tingkat detail informasi geografis dan dapat mengurangi kegunaan informasi ini bagi investor. Hasil pemetaan yang menunjukkan bahwa mayoritas perusahaan di Indonesia mengungkapakna dalam level geografis yang detail, kemungkinan menjadikan salah satu argument yang menguatkan penurunan dalam segmen yang lain yakni untuk mengurangi tingkat kerugian kompetitif yang mungkin ditimbulkan dalam informasi segmen. Perilaku pengungkapan ini dapat dirasionalisasikan melalui PCT dimana secara spesifik segmen geografis yang dilaporkan, akan menunjukkan semakin tinggi risiko (dan biaya) perusahaan terhadap pengungkapan informasi. Untuk mengurangi peningkatan risiko pengungkapan informasi kepemilikan sesuai dengan persyaratan standar informasi akuntansi perusahaan memilih mendefinisikan secara rigid informasi segmen geografis.

\begin{tabular}{lc}
\hline \multicolumn{1}{c}{ Level of Specificity } & $2012-2017$ \\
\hline Single Country Segments & $16,67 \%$ \\
Two-Country segments & $0 \%$ \\
Single-Region or Single Continent Segments & $16,67 \%$ \\
Two-or-more-regions or two-or-more continents segments & $33,33 \%$ \\
Rest of The world segments & $33,33 \%$ \\
\hline
\end{tabular}

Tabel 2.

Perubahan Jumlah Segmen

\section{SIMPULAN}

Informasi dalam laporan segmen merupakan informasi yang paling penting bagi para stakeholder dalam rangka pengambilan keputusan. Laporan segmen menyediakan informasi mengenai berbagai jenis segmen (line of business) yang dijalankan oleh perusahaan dan lingkungan geografis tempat perusahaan beroperasi. Informasi ini tentunya membantu stakeholder untuk meningkatkan pemahaman mengenai kinerja perusahaan, penaksiran arus kas masa depan, dan penilaian atas perusahaan secara keseluruhan. Kebergunaan pengungkapan informasi dalam laporan segmen mendorong badan standar untuk membuat pedoman yang mengatur pengungkapan informasi segmental melalui IAS 14. Perubahan standar terbaru dari IAS 14 menjadi IFRS 8 memunculkan keraguan stakeholder karena memberikan kelonggaran bagi manajemen untuk memilih jenis informasi segmen-

Tabel 3.

Daftar level segmen geografis 
Pengungkapan Jumlah

Segmen...

164

tal yang akan dilaporkan (Veron, 2007). Perubahan standar pengungkapan informasi segmental dari IAS 14R ke IFRS 8 tentunya turut mengubah standar pelaporan yang berlaku di Indonesia, yaitu dari PSAK 5 menjadi PSAK 5R. Pengaruh perubahan standar ini tentunya perlu diketahui untuk dapat menentukan keefektifan standar yang baru.

Berdasarkan periode amatan 2012-2017 setelah perubahan standar, pengaruh perubahan standar dilihat melalui 2 jenis informasi yang disajikan dalam laporan segmen. Pertama, jumlah dan jenis segmen, hasil penelitian menujukkan bahwa perubahan standar menurunkan pengungkapan atas segmen LOB dan geografis masing masing sebesar $4 \%$ dan $2 \%$. Kedua, pada level geografis, perusahaan di Indonesia cenderung mengungkapakan dengan lebih rigid dan detil yakni pada level 5 dan 4. Perubahan dalam masa setelah adopsi penting untuk diteliti karena membantu stakeholder untuk memahami dampak perubahan aturan. Periode yang dipilih untuk menilai dampak perubahaan cukup singkat sehingga menjadi keterbatasan penelitian ini. Penelitian selanjutnya dapat meneliti dampak perubahan lebih lanjut setelah pemberlakuan standar baru dalam waktu yang lebih lama. Penelitian pada periode ini dapat menjadi landasan untuk penelitian selanjutnya. Penelitian selanutnya juga dapat menilai pengaruh perubahan berdasarkan aspek informasi segmental lain, seperti keakuratan forecast dan juga terkait adanya disadvantage information berdasarkan penggunaan standar berbasis IFRS 8 di Indonesia.

\section{DAFTAR PUSTAKA}

Aleksanyan, D., and J. Danbolt. 2015. "Segment Reporting: Is IFRS Really Better?". Accounting In Europe. Vol,12 No.1.

Baldwin, B. 1984. "Segment Earnings Disclosure and The Ability Of Security Analysts to Forecast Earnings Per Share". The Accounting Review.

Behn, B.K., Nicholas, N.B., and Street, D.L. 2002. The Predictive Ability Of Geographic Segment Disclosures by U.S. Companies: SFAS No. 131 Vs. SFAS.

Birt, J., and Greg Shailer. 2011. "Forecasting Confidence Under Segment Reporting”. Accounting Research Journal. Vol. 24. No.3.

Boatsman, J., Behn, B., and Patz, D. 1993. "A Test Of Geographical Segment Disclosure”. Journal Of Accounting Research. Vol.31(Suppl.).

Crawford, L., Ferguson, J., Helliar, C., and Power, D. 2014. "Control Over Accounting Standards Within The European Union: The Political Controversy Surrounding The Adoption Of IFRS 8". Critical Perspectives On Accounting. Vol. 24. No. 4-5.

Ettredge, M.L., Kwon, S.Y., Smith, D.B.. and Zarawon P.A. 2005. "The Impact of SFAS 131 Business Segment Data on Market's Ability to Anticipate Future Earnings". Accounting Review. Vol. 80. No.4.

Fatmawati, DS., and A. Pratiwi. 2018. "Segment Reporting: The Beginning of Transition Period In Indonesia". Review of Integrative Business and Economics Research. Vol.7. No.3.

Herrmann, D. 1996. "The Predictive Ability of Geographic Segment Information at The Country, Continent, and Consolidated Levels". Journal Of International Financial Management and Accounting, Vol. 8. No.1.

Hope, O. K., Thomas, W., and Vasvari, F. 2009. "The Effect Of SFAS $131 \mathrm{Geo}^{-}$ graphic Segment Disclosure by U.S. Multinational Companies On The Valuation of Foreign Earnings". Journal Of International Business Studies. Vol.40. No.3. 
International Accounting Standards Board (IASB). 2013. Post-Implementation Review: IFRS 8 Operating Segments, Report And Feedback Statement. London. International Accounting Standards Committee Foundation.

Lobo, G.J., Kwon, S.S., and Ndubizu, G.A. 1998. "The Impact of SFAS No. 14 Segment Information On Price Variability and Earning Forecast Accuracy". Journal Of Business Finance and Accounting. Vol.25 No.7.

Maines, L.A., McDaniel, L.S., and Harris, M.S. 1997. "Implications Of Purposed Segment Reporting Standards For Financial Analysts' Investment Judgments". Journal Of Accounting Research. Vol.35.No.1.

Martani, Dwi, S. Veronica, R. Wardhani, A. Farahmita and E. Tanujaya. 2012. Akuntansi Keuangan Menengah. Salemba Empat. Jakarta.

Nichols, D., Tunnell, L., and Seipel, C.1995. "Earning Forecast Accuracy and Geographical Segment Disclosures". Journal Of International Accounting and Auditing and Taxation. Vol.4.No.2.

Radebaugh, L.H., and Gray, S.J. 2002. International Accounting Multinational Enterprise. Wiley. NewYork.

Veron, N. 2007. EU Adoption Of The IFRS 8 Standard on Operating Segments. Report to The Economic and Monetary Affairs Committee Of The European Parliament. 
